whose doctor did nothing to supplement her maintenance treatment in order to help her meet the crisis. There are 24 surviving patients, and they are now in positively good health in contrast to their state of semi-invalidism in the preceding era. Many of them do hard labouring work without difficulty, and indeed were I faced as a young man with choosing whether I would rather have Addison's disease or diabetes I think I would choose the former. Its treatment is simpler than that of diabetes; with care the expectation of life should not be shortened, and so far as we know there are no Addisonian complications comparable to those of diabetes. There are few other conditions which illustrate more completely the triumphs of modern chemotherapy.
REFERENCES

Anderson, J. R., Goudie, R. B., Gray, K. G., and Timbury, G. C. (1957). Lancet, 1, 1123.

Blizzard, R. M., Chandler, R. W., Kyle, M. A., and Hung, W. (1962) Ibid., 2, 901

Briggs. J. N., Goodwin, J. F., and Wilson, A. (1951). Brit. med. J., 1, 115 .

Brøchner-Mortensen, K. (1956). Acta med. scand., 46, 205.

Brownie, A. C., and Sprunt, J. G. (1962). Lancet, 1, 773.

Fahr, T., and Reiche, F. (1919). Frankfurt. Z. Path., 22, 231.

Guttman, P. H. (1930). Arch. Path., 10, 742.

Liddle, G. W., Estep, H. L., Kendall, J. W., Williams, W. C., and Townes, A.. W. (1959). J. clin. Endocr., 19, 875.

Moehlitg, R. C. (1947). Ibid., 7, 134

Morse, W. I., Cochrane, W. A., and Landigran, P. L. (1961). New Engl. J. Med., 264, 1021 .

Neumann, J. (1916). Münch. med. Wschr., 63, 488.

Thorn, G. W., Dorrance, S. S., and Emerson, D. A. Y. (1942). Ann. intern. Med., 16. 1053.

\title{
MALIGNANT LYMPHOMA OF THE TESTIS
}

\author{
BY \\ H. ECKERT, M.D., D.M.R.T. \\ Christie Hospital and Holt Radium Institute, Manchester \\ J. P. SMITH, M.D.
}

[With Special Plate]

Malignant lymphoma is a collective term for all tumours of lympho-reticular origin, and, although many structural variations occur, they are generically sarcomas of the pluripotential reticular stem cell. Malignant lymphoma of the testis is a neoplasm presenting chiefly in later life, usually of rapid onset and commonly progressing to a fatal conclusion by generalized dissemination, becoming indistinguishable from generalized lymphosarcomatosis.

Relatively few cases of malignant lymphoma of the testis have been recorded. Curling (1878) mentions one seen by him in 1865 and two others, including that of Malassez (1877), who gave the first full description. More recently Ennuyer et al. (1960) have reviewed 34 cases from the literature and added two of their own.

It is the purpose of this paper to report 35 further cases, describe the natural history of the disease, and establish its existence as a primary condition of the testis.

Source of Material.-One of us (J.P.S.) has reviewed the pathology from 665 patients with testicular tumour registered at the Christie Hospital from the beginning of 1946 to the end of 1962 . Of these, $35(5.3 \%)$ have been recognized as falling into the lympho-reticular group of diseases.

\section{Pathology}

Malignant lymphomas of the testis are rapidly growing tumours and usually are large by the time they are first seen. The largest in our series measured 13 by 10 by $8 \mathrm{~cm}$.

The tunica albuginea always appears to be intact, and may be smooth or lobulated. The cut surface shows soft white or cream-coloured tumour, usually destroying the body of the testis completely and often invading the epididymis. The tumour may be diffuse or divided into lobules by fibrous septa. Necrosis and haemorrhage may occur. Two of our cases show diffuse infiltration and two others nodular masses of tumour in the spermatic cord.

Microscopically, most of these tumours are composed of polymorphic, often angular, reticulum cells (Special Plate, Fig. 1) with considerable reticulin formation, almost to the extent of surrounding individual cells (Special Plate, Fig. 2). The typical tumour spreads in sheets between widely separated atrophic testicular tubules (Special Plate, Fig. 3). Mitoses are common, and invasion of the walls of veins is often seen. In two cases the appearances were of a more lymphocytic type of tumour, and in another they were those of a plasmacytoma.

\section{Clinical Features}

In 30 of the 35 patients the presenting feature was a testicular tumour which was usually painless. Of the remainder, the maxillary antra were affected at the onset in two (Cases 1 and 2), thigh muscle in one (Case 3), a vertebra in one (Case 4), and in another the disease was generalized throughout the lymphatic system when first seen (Case 5).

The mean age of the group is 59.8 years, which compares with a mean age of 33 years for the teratomas and 42.3 years for the seminomas in our series. The age distribution of these tumour types is shown in Fig A.

The left testis was involved in sixteen cases and the right in fourteen. In five the lesions were bilateral, three apparently of simultaneous onset and two affecting the right side two and four years before the left (Cases 6 and 7).

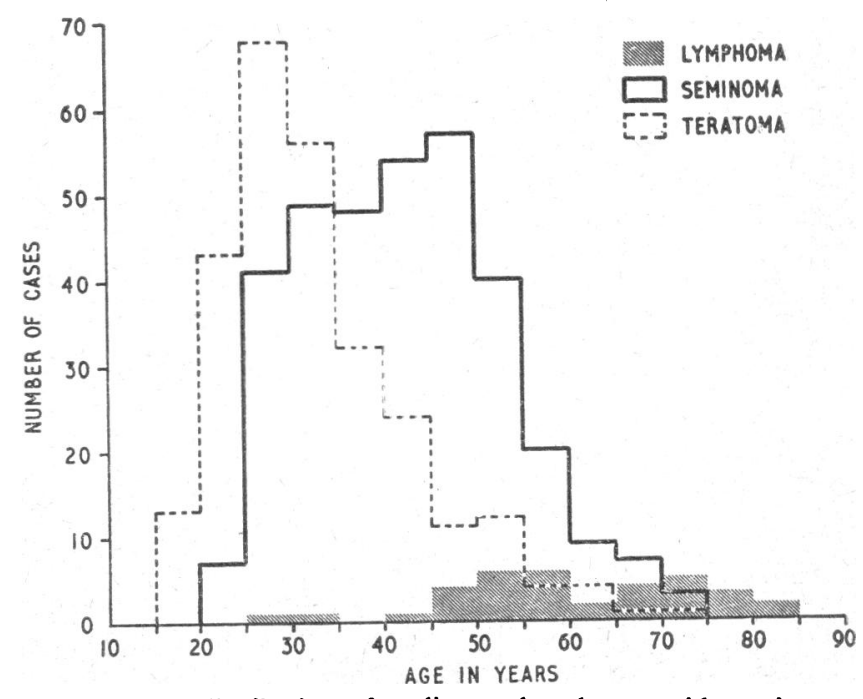

Fig. A.-Age distribution of malignant lymphoma, with seminoma and teratoma shown for comparison. 


\section{Treatment}

All cases had an orchidectomy, and in 23 this was followed by deep $x$-ray therapy to the whole abdomen. The majority were treated by the Manchester trunk bridge. Eight of the more recent patients were treated by the 4-MeV linear accelerator, the field including the scrotum and inguinal, iliac, and para-aortic lymph-node areas. The techniques have been fully described by Gibb (1960).

\section{Results}

Of the 35 patients, 26 died of generalized disease, 20 (57\%) within 18 months of onset. A variety of organs were ultimately affected, and an analysis of the sites is shown in Table $I$ and illustrated by the cases described.

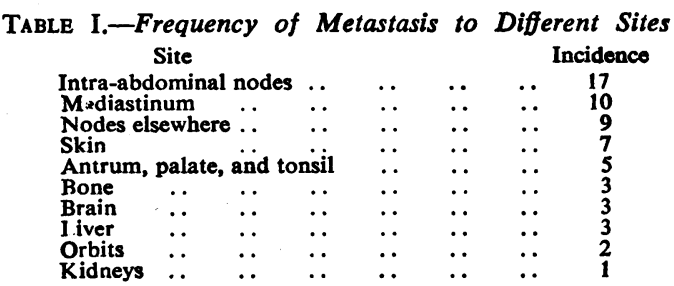

TABle II.-Details of Survivors, and Patients Who Have Died from Unrelated Conditions

\begin{tabular}{|c|c|c|c|c|c|c|}
\hline Case & Age & $\begin{array}{c}\text { Testis } \\
\text { Involved }\end{array}$ & $\begin{array}{c}\text { Months } \\
\text { before } \\
\text { Seeking } \\
\text { Treat- } \\
\text { ment }\end{array}$ & Treatment & $\begin{array}{l}\text { Survival } \\
\text { from First } \\
\text { Symptom }\end{array}$ & Cause of Death \\
\hline $\mathbf{A}$ & 73 & $\mathbf{L}$ & 6 & ) & 9 years & Myocardial \\
\hline $\mathbf{B}$ & 81 & $\mathbf{L}$ & 5 & Orchi- & $4 t "$ & $\begin{array}{l}\text { Cerebral } \\
\text { thrombosis }\end{array}$ \\
\hline$\underset{\mathbf{D}}{\mathbf{C}}$ & $\begin{array}{l}71 \\
64\end{array}$ & $\begin{array}{l}\mathbf{R} \\
\mathbf{R}\end{array}$ & $\begin{array}{l}6 \\
2\end{array}$ & dectomy & 8 months & $\begin{array}{l}\text { Hypertensive } \\
\text { nephrosclerosis }\end{array}$ \\
\hline $\begin{array}{l}\mathbf{E} \boldsymbol{t} \\
\mathbf{P} \\
\mathbf{G} \\
\mathbf{H}\end{array}$ & $\begin{array}{l}58 \\
59 \\
58 \\
54\end{array}$ & $\begin{array}{c}\text { Bilateral } \\
\mathbf{R} \\
\mathbf{R} \\
\mathbf{R}\end{array}$ & $\begin{array}{l}4 \\
3 \\
6 \\
5\end{array}$ & $\left\{\begin{array}{l}\text { Orchidect- } \\
\text { omy plus } \\
\text { abdominal } \\
x \text {-ray }\end{array}\{\right.$ & $\begin{array}{l}11 \text { years } \\
99 " \\
6 \\
18 \text { mönths }\end{array}$ & Alive and well \\
\hline I¥ & 57 & $\mathbf{R}$ & 6 & Orchidectomy & $8 "$ & \\
\hline
\end{tabular}

Four patients died from unrelated conditions with no evidence of lymphomatous disease and five are still alive. Details of these nine cases are given in Table II. Three of them survived for some years after orchidectomy alone (Cases $A, B$, and C), radiotherapy having been withheld in view of their age. The delay before seeking treatment was average in all these cases, and the cause of death in the first four could not be related in any way to the testicular condition.

The delay from the first symptom to the seeking of treatment, which ranged from one month to two years (mean 5.4 months), does not influence the survival time. In the 26 patients dead of disseminated disease, survival from the first symptoms varied from four months to three and a half years (Fig. B), with a mean of 14.7 months. Only seven patients survived three years from orchidectomy, and only four of these were treated with $x$ rays. There are only four five-year survivors $(11.4 \%)$.

\section{Illustrative Cases}

Case 1.-The first symptom affecting this 48year-old man was nasal discharge, followed by right-sided nasal obstruction. It was not until four months later, when his right testis became swollen, that he sought advice. Biopsy of the nasal tumour and an orchidectomy showed the typical appear- ances of malignant lymphoma. Radiographs of the right antrum showed opacity but no bone destruction. He was given wide-field $x$-ray therapy to the head and neck. Within four months of this he developed abdominal metastases and died.

Case 2.-A 50-year-old man had a ten-months' history of increasing swelling of the right side of his face with recent onset of nasal obstruction. On examination he had a grossly swollen face (Fig. C), and a large, hard right testis, of which condition he had not been aware. Orchidectomy revealed a testicular tumour weighing $380 \mathrm{~g}$. The tunica was thickened and showed dilated tortuous veins over its surface. The cut surface showed a lobulated tumour with a soft, almost gelatinous consistency, with areas of haemorrhage. The histological appearances were those of a polymorphic plasmacytoma.

After orchidectomy he was given $x$-ray therapy to the face, with a sensitive response (Fig. D). He remained symptom-free for a year, when he was admitted to a neurosurgical unit in a semicomatose state from which he did not recover. Necropsy revealed in a temporal lobe of the brain a secondary tumour which was also a plasmacytoma.

Case 3.-This 71-year-old patient noticed a swelling of the outer aspect of his right thigh in April, 1955, which gradually enlarged until it was excised five months later. Six months after this operation he complained of a right testicular swelling. Orchidectomy was followed by abdominal $x$-ray therapy. In November, 1956, skin metastases and enlarged cervical lymph nodes developed and he died shortly of disseminated disease. Pathological diagnosis: malignant lymphoma.

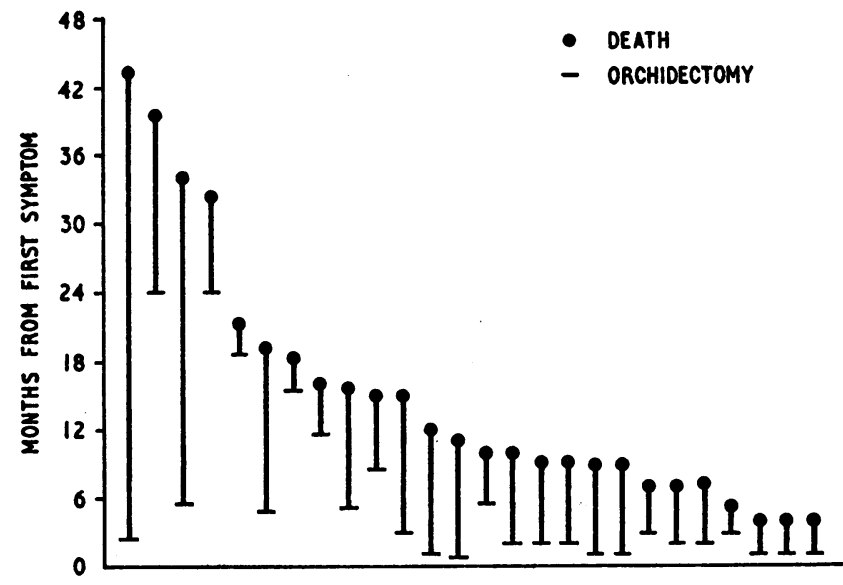

Fio. B.-Survival of malignant lymphoma from first symptoms and from orchidectomy in those patients dead of the disease.

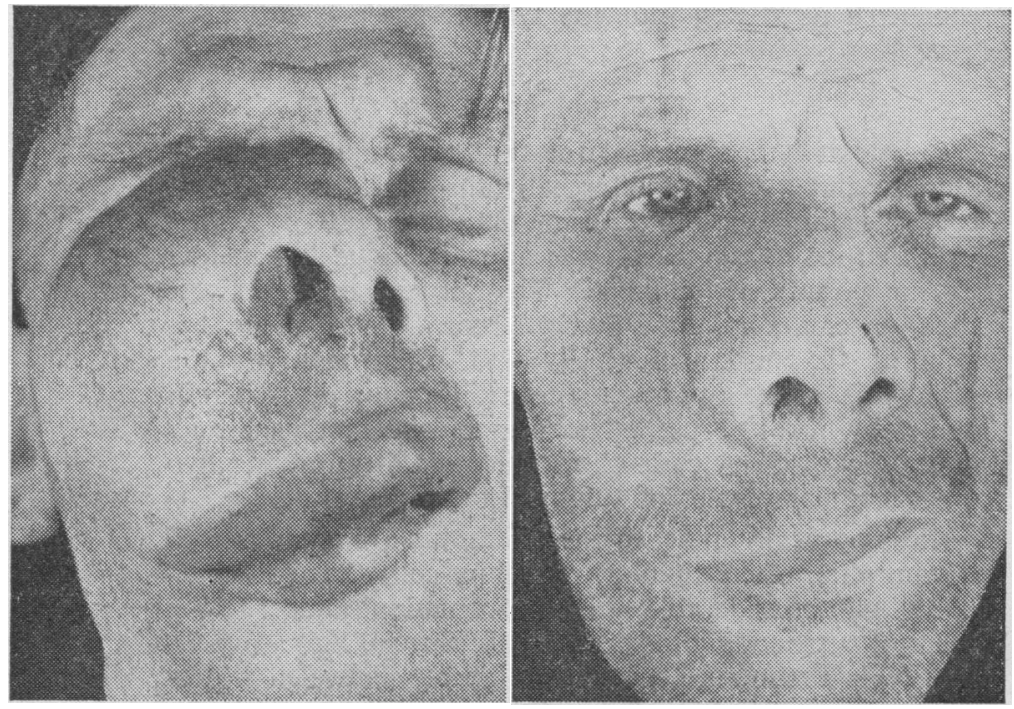

P10. C.-Case 2. Showing gross swelling of face. Fio. D.-Case 2. Sensiuve response to $x$-ray therapy. 
Sir DERRICK DUNLOP : 86 CASES OF ADDISON'S DISEASE

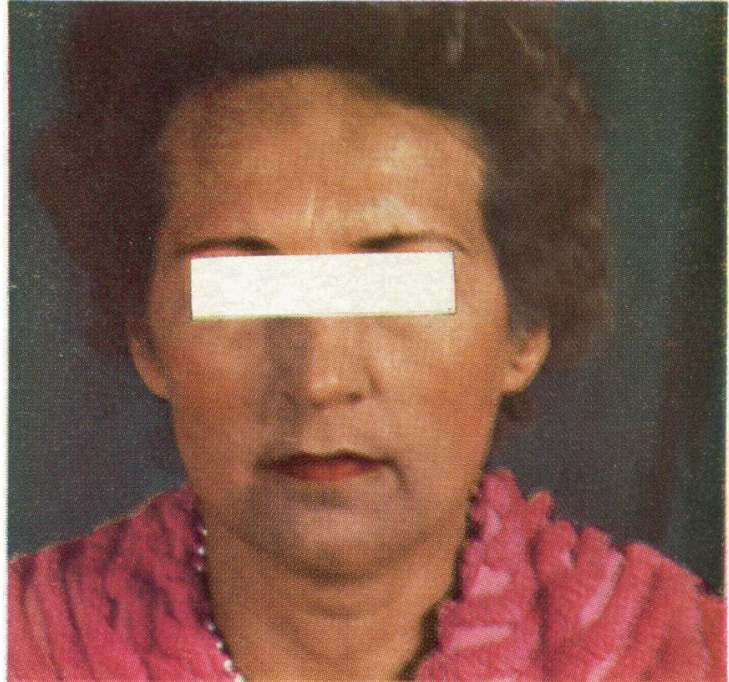

Fig. 1

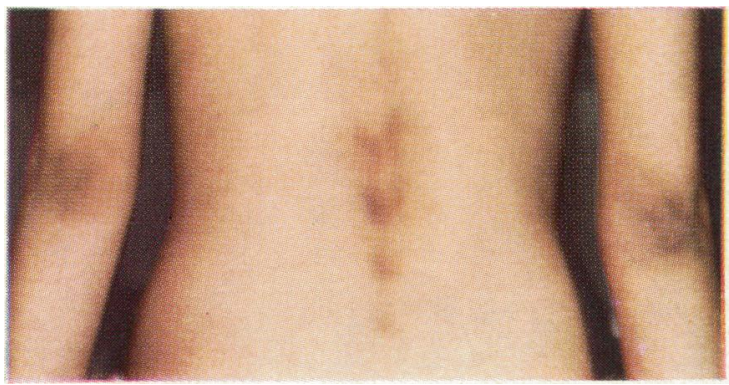

Fig. 2

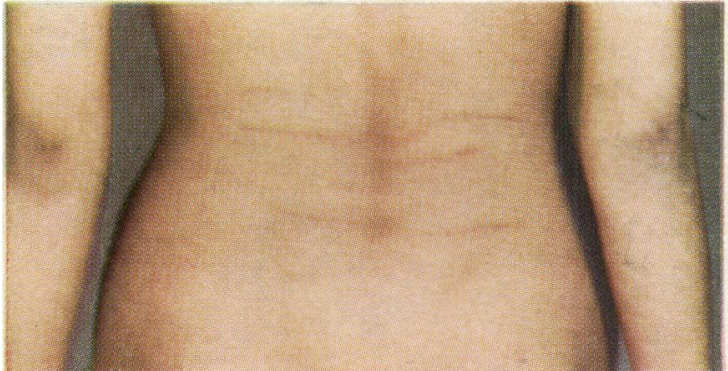

FIG. 3

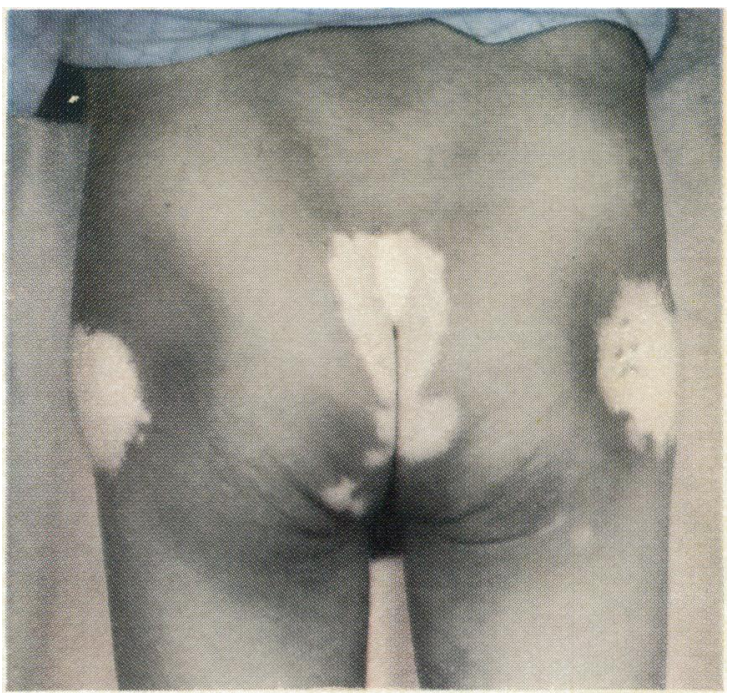

FIG. 4

\section{H. ECKERT AND J. P. SMITH: MALIGNANT LYMPHOMA OF THE TESTIS}

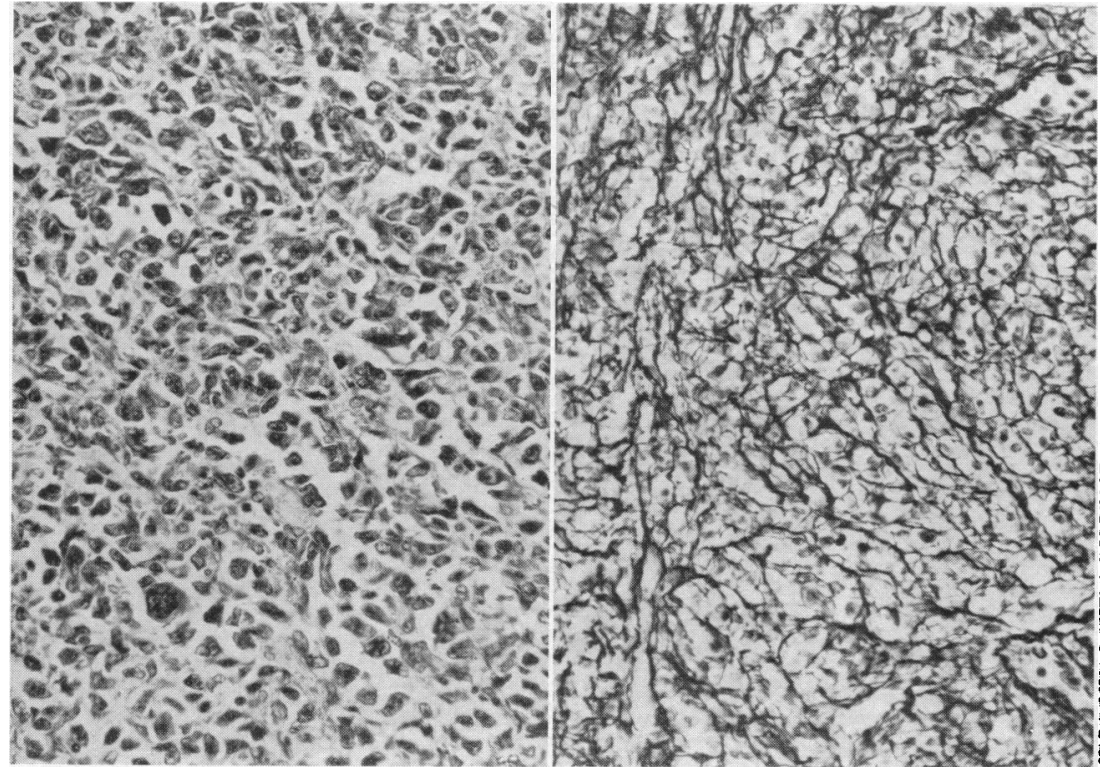

FIG. 1.-Section showing tumour composed of polymorphic angular cells. (H. and $\mathrm{E} . \quad \times 215$.)
FIG. 2.-Section showing dense reticulin network. (Reticulin stain. $\times 215$.)

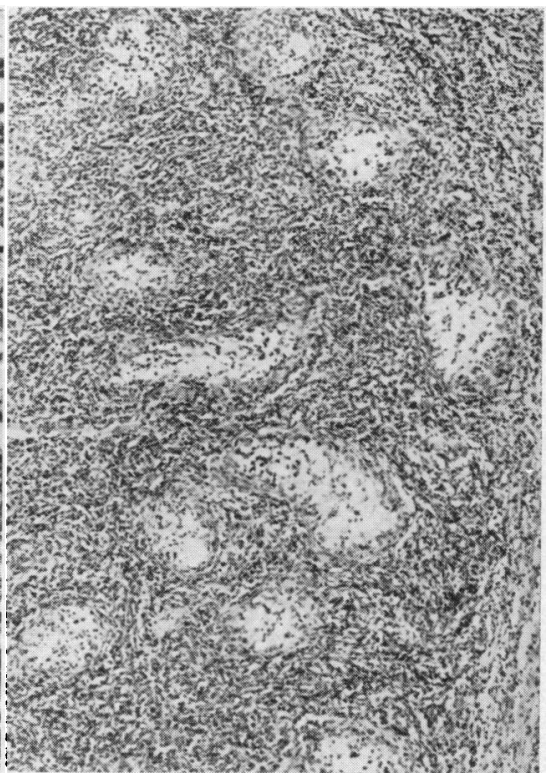

FIG. 3.-Section showing diffuse infiltration of tumours amongst atrophic testicular tubules. $(\mathrm{H}$. and $\mathrm{E}$. $\times 60$.) 
Case 4.-For six months this 57-year-old man had been suffering from severe lumbar pain. No abnormality was found on examination. The testes were noted to be normal. Radiographs revealed destruction of the second lumbar vertebra, but further investigations, including blood and marrow examination, electrophoresis of serum proteins, skeletal survey, and an intravenous pyelogram, were all normal. $X$-ray therapy was given to the affected vertebra. Two months later he complained of enlargement of the right testis. Orchidectomy was performed and a histological diagnosis of malignant lymphoma made. The assumption that the vertebral lesion is a manifestation of the same condition can fairly be made, but the patient has been under review for only a short time.

Case 5.-At the age of 28 this patient noticed a swelling in his left groin. A year later he developed a mass in the left axilla followed within a month by pain in the left loin, jaundice, night sweats, and pyrexia. On examination he was anaemic (Hb $5.3 \mathrm{~g} . / 100 \mathrm{ml}$.) and jaundiced. Both eyes were proptosed, and, as well as the nodes he had noticed, there was a large mass in the left abdomen and a hard swelling of a solitary left scrotal testis. The right testis was presumed to be undescended. Biopsy of the axillary mass and an orchidectomy revealed a lymphosarcomatous type of malignant lymphoma. Local palliative $x$-ray therapy was given to the orbits and residual masses, but he rapidly developed skin metastases and within a few weeks died of disseminated disease.

Case 6.-In June, 1951, at the age of 58, this man developed a painless swelling of the right testis. In October of that year right orchidectomy was carried out and prophylactic $x$-ray therapy given to the whole abdomen. Four years later the left testicle became enlarged and was excised. The pathology of both testes was malignant lymphoma. Further $x$-ray therapy could not be given, but he remains well 11 years after the first operation.

Case 7.-A swelling of the right testis was noticed by this patient at the age of 47 . He ignored this until two years later, when his left testis became enlarged. At this time he also had

\section{LEGENDS TO SPECIAL PLATE}

PLATE I : Left optic fundus $1 \frac{1}{4}$ minutes after onset of attack. -The disk and retina are pale and the arteries, containing dark blood, are difficult to distinguish from the veins. The branches of the central artery of the retina arising out of the disk, are filled with a white material which extends in the superior nasal and superior temporal arteries to just beyond their first major divisions. In the distal portions of beyond their first major divisions. In the distal portions of the arteries small pieces of white material break up the
columns of blood to give a segmented appearance, and the columns of blood to give a segmented appearance, and the
distinct interfaces have various contours. In the superior temporal artery at the edge of the disk a small plug of blood is sandwiched between two columns of white material.

Plate II : $3 \frac{1}{4}$ minutes after onset of attack:-The embolic material is advancing into the superior nasal and temporal arteries, pushing the small plug of blood further up the arteries, is advancing into the superior nasal and temporal superior puspor three branches of this vessel. The radiating pattern of nerve fibres is becoming more easily visible in the relatively blood-
less zone on either side of the superior temporal artery.

Platb III : 4 minutes after onset of attack.-The embolus is flowing mainly into the superior temporal artery, carrying upward the attenuated plug of blood towards the first major division of the vessel. Small veins running direct to the disk are now almost empty, although the major venous tributaries do not seem to have changed in calibre.

Plate IV : 41 minutes after onset of attack. - Suddenly the embolus has been displaced and oxygenated blood is filling the arterial tree except for the inferior nasal artery, in which the arterial tree except for the inferior nasal artery, in which has returned to the retina and the veins are dilated. There is no cherry-red spot at the macula.

Plate V: $4 \frac{3}{4}$ minutes after onset of attack. -The embolus in the inferior nasal artery has been dislodged and blood is passing through this artery. Venous dilatation and hyperaemia persist.

Frg. 1: Left carotid angiogram.-Contrast dye, entering the common carotid artery, is filling the external carotid artery and its branches. A total occlusion of the internal carotid artery at its origin prevents filling of this vessel and its artery at its origin prevents filling enlarged right cervical lymph nodes and a tumour of the hard palate (Fig. E). Bilateral orchidectomy and palatal biopsy were carried out and malignant lymphoma of these sites was diagnosed. He was given a course of $x$-ray therapy to the neck and palatal region, and this was followed three months later, when he developed an upper abdominal mass, by abdominal $x$-ray treatment. Resolution of the tumours was good at first, but he died of disseminated disease seven months after the orchidectomy had been performed.

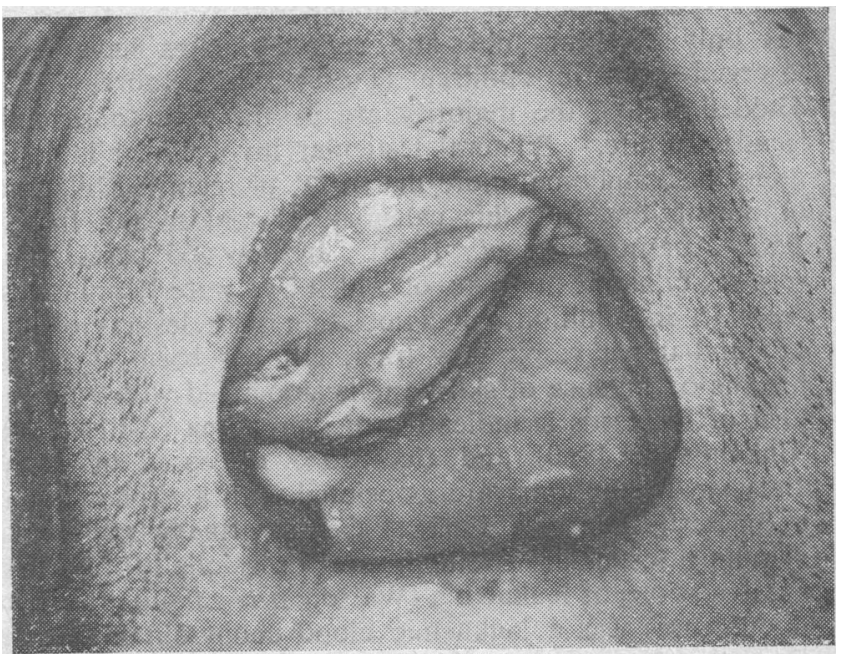

Fig. E.-Case 7. Malignant lymphoma of the hard palate.

Case 8.-This 57-year-old man had an orchidectomy for a painless swelling of the left testis of five months' duration. There was no other evidence of disease, and post-operative $x$-ray therapy was given to the whole abdomen. During his four-weeks course of treatment the right tonsil became enlarged and ulcerated. Local $x$-ray therapy was given to this area with good response. Six months after this he complained of increasing lassitude and dyspnoea. There were multiple subcutaneous nodules over the chest wall, and radiographs revealed a large mediastinal mass with bilateral pleural effusions. He died shortly afterwards, and at necropsy there was a solid mass of tumour extending continuously from the para-aortic lymph nodes through the diaphragm, occupying most of the mediastinum and thoracic inlet and extending into the neck. The pathology of the testicular and metastatic tumours was malignant lymphoma.

\section{Discussion}

The term malignant lymphoma has been used to include all types of malignant lympho-reticular disease, and, in our experience, is the commonest secondary testicular tumour. The existence of primary malignant lymphoma of the testis has been disputed. Chevassu (1906) considered them all to be embryonal tumours or seminomas, while others (Pease and McDonald, 1947 ; Ficari, 1950) regarded them as being always secondary to disease elsewhere.

When the testis appears to be the only site involved by malignant lymphoma it is impossible to state unequivocally whether a localized or generalized process exists. In this series testicular swelling was the first sign of disease in 30 patients. However, 20 were dead within 18 months, suggesting that the condition was generalized by the time the swelling was noticed. In the first seven cases from Table II it appears that the testis was the primary and sole site. This is certainly so in the first three cases, whose survival, after orchidectomy alone, was longer than that of any of these patients dying of metastases. In Case D from this Table post-mortem examination six months after orchidectomy failed to reveal any residual tumour, although careful search was made. Of the three patients surviving 11,9 , and 6 years after treatment by orchidectomy and 
$\boldsymbol{x}$ rays it may be argued that involved abdominal lymph nodes had been cured by the radiotherapy. However, it would still appear probable that the testis had been the primary site. Especially is this so in Case E, still alive seven years from the second orchidectomy, which was not tollowed by $x$-ray therapy.

The natural history of these tumours differs from that of other testicular neoplasms. Lymphomas tend to occur in the older age-group. Although our youngest patient was only 28 years old, and sporadic cases have been observed even in children (Turley and Moore, 1952; Waddell, 1961), the majority are in the fifth to seventh decades of life. Bilateral testicular involvement is commoner in lymphoma, more than $50 \%$ of recorded bilateral tumours falling into this category (Hotchkiss and Laury, 1950 ; Abeshouse et al., 1955). In our 665 cases there were six bilateral tumours, of which five were lymphomas. There is, in addition, an association with lesions of the skin and upper respiratory tract. It has been suggested that the occurrence of skin lesions associated with enlargement of the testis is indicative of lymphoma (Altman and Winkelmann, 1960) and that $20 \%$ of cases of nasopharyngeal lymphoma are associated with a similar lesion in the testis (Varney, 1955). Genito-urinary symptoms, including testicular swelling, are occasionally the first manifestations of leukaemia (Watson et al., 1949). In none of our cases was a leukaemic blood count obtained even when the disease was widespread. The $11.4 \%$ survival rate at five years compares unfavourably with that of other testicular tumours, in which an overall $50 \%$ five-year survival may be expected (Boden and Gibb, 1951).

The single case of plasmacytoma we have described has been included for interest. Its occurrence in this site is rare, and it always appears to be part of a generalized process (Hayes et al., 1952 ; Melicow and Cahill, 1954).

\section{Summary and Conclusions}

The pathology of 665 cases of testicular tumour has been reviewed. Of these, 34 have been recognized as malignant !ymphoma and one as plasmacytoma.
The pathology, clinical features, and results of treatment of this group are described and illustrative cases presented. The existence of primary malignant lymphoma of the testis is established and the natural history of the disease discussed and compared with that of other testicular tumours.

Primary lymphoma of the testis is a recognizable entity which should be suspected in all cases of testicular tumour occurring over the age of 60 . There is a tendency for bilateral involvement and an association with lesions of the skin and upper respiratory tract. The prognosis is poor, although some long-term survivals occur. There appear to be no distinguishing features, either clinical or pathological, which would enable these fortunate few to be recognized.

We wish to thank Dr. Robert Gibb for encouragement and valuable criticism. Material from 32 of our cases has been available for submission to the Testicular Tumour Panel and Registry, of which one of us (J.P.S.) is a member. We wish to acknowledge the help received from the Panel in the study of these cases.

REFERENCES

Abeshouse, B. S., Tiongson, A., and Goldfarb, M. (1955). J. Urol. 74,522 .

Altman, J, and Winkelmann, R. K. (1960), Arch. Derm., 82, 943. Boden, G., and Gibb, R. (1951). Lancet, 2, 1195

Curling, T. B. (1878). A Practical Treatise on the Diseases of the Testis, 4th ed., p. 353. Churchill, London.

Ennuyer, A., Gricouroff, G., and Thivet, M. (1960). J. Radiol. Electrol., 41, 791

Ficari, A. (1950). J. Path. Bact., 62, 103

Gibb, R. (1960). Proc, roy. Soc. Med., 53, 235.

Hayes, D. W., Bennett, W. A., and Heck, F. J. (1952). Arch. Path., 53, 262.

Hotchkiss, R. S., and Laury, R. B. (1950), J. Urol., 63, 1086

Hotchkiss, R. S., and Laury, R. B. (1950), J. Urol.,
Malassez, M. (1877). Bull Soc. anat. Paris, 52, 176.

Malassez, M. (1877). Bull Soc. anat. Paris, 52, 176. $1,103$.

Pease, G. L., and McDonald, J. R. (1947). Amer. J. clin. Path., 17 181

Turley, H. K., and Moore, T. D. (1952). J. Urol., 68, 744

Varney, D. C. (1955). Ibid., 73, 1081.

Waddell, R W (1961) Ibid, 85, 956.

Watson, E. M., Sauer, H. R., and Sadugor, M. G. (1949). Ibid 61, 626 .

\title{
RECURRENT TRANSIENT MONOCULAR BLINDNESS
}

\author{
MICHAEL ASHBY, B.M., M.R.C.P. \\ NIGEL OAKLEY, M.B., M.R.C.P. \\ IVAN LORENTZ, M.B., M.R.C.P. \\ Department of Neurology, the Whittington Hospital, London \\ DAVID SCOTT,* M.B., M.R.C.P. \\ Department of Medicine, Postgraduate Medical School of London, London
}

\section{[With Special Plate]}

There are over thirty published descriptions of the ophthalmoscopic appearances during attacks of transient monocular blindness, yet the absence of reliable drawings, photographs, or even detailed descriptions makes it impossible, in the majority of cases, to obtain much useful information about the cause of the condition.

This is well illustrated by Fisher's (1959) difficulty in dividing previous reports into two main aetiological groups; different classifications are assigned to two separate accounts of a single patient (Harbridge, 1906 ; Zentmayer, 1907), and, in fact, most of the cases end up under a third reading-“"miscellaneous." It is further supported by Russell (1961), who includes in his paper retinal photographs showing appearances without clear aetiological

-In receipt of a research grant from the British Diabetic Association. significance, although his text implies that the ophthalmoscopic changes were undoubtedly those of retinal embolism.

The main object of this paper is to present a sequence of retinal photographs taken during one of over twenty attacks of transient monocular blindness experienced by a man with thrombosis of the ipsilateral internal carotid artery, and to discuss the objective findings thus recorded.

\section{Historical Background}

Shortly after the introduction of the concept of embolism von Graefe (1859) suggested it as a possible mechanism in cases of monocular blindness; subsequently this aetiology became generally accepted, and when Coverdale (1929) described 11 cases of central retinal artery occlusion he concluded that "the most satisfactory explanation of the great majority of cases . . . is embolism," and that " there 